ORIGINAL ARTICLE

\title{
Cosmetic Use and Its Adverse Events among Female Employees of Jimma University, Southwest Ethiopia
}

\author{
Mestawet Getachew $^{1 *}$, Tsegaye Tewelde ${ }^{2}$
}



\author{
ABSTRACT
}

BACKGROUND: Cosmetics is applied to human body for cleansing, beautifying, promoting attractiveness or altering appearance. Cosmetics is causing alarming adverse events to its users, yet evidence about its magnitude and cosmetic use among female employees in Ethiopia is limited. Therefore, this study was aimed at determining cosmetic use and its adverse events among female employees of Jimma University.

METHOD: A cross-sectional study was done among female employees from December 2016 to January 2017. Samples of 426 participants were selected using stratified simple random sampling from all colleges, and data were collected using self-administered questionnaire. Descriptive statistics was used to compute proportions and logistic regression to assess the determinants of cosmetics-related adverse events.

RESULTS: A total of 387 females were participated, making a $\mathbf{9 0 . 8 \%}$ response rate. The majority (80.1\%) were using at least one cosmetic product, and $39.0 \%$ of them were between 25-29 years. The majority (86.6\%) of the respondents used toothpaste, lotion, lipstick, or eye makeup. Cosmetics related adverse events were experienced by $19.0 \%$ of the respondents primarily on face and hairs. Lotion and hair cosmetics were the primary perceived causes of adverse events. Employees who had monthly income between 1000 and 3000 ETB (AOR=3.4; 95\% CI: 1.4-8.4), above 3000 ETB (AOR=4.7; 95\% CI: 1.8-12.2) and those who used traditional cosmetics (AOR=4.5; 95\% CI: 2.1-9.6) were more likely to develop adverse events.

CONCLUSION: A significant proportion of the users suffered from cosmetics related adverse events. The female employees have to be aware of the rational cosmetics utilization practices to minimize adverse events.

KEYWORDS: Cosmetic use, adverse events, female employee, Jimma University, Southwest Ethiopia

\section{INTRODUCTION}

Cosmetics is defined by their intended use as a material rubbed, poured, sprinkled, or sprayed on, introduced into, or otherwise applied to the human body for cleansing, beautifying, promoting attractiveness, or altering the appearance. Among the products 
included in this definition are skin moisturizers, perfumes, lipsticks, fingernail polishes, eye and facial makeup preparations, cleansing shampoos, permanent waves, hair colors, medicated soaps and deodorants, as well as any substance intended for use as a component of a cosmetic product (1). However, products intended to treat or prevent disease, or affect the structure or function of the body, are considered drugs. Nevertheless, some products like anti-dandruff shampoos, anti-perspirant deodorants, and makeup with SPF (sun protection factor) meet the definitions of both drugs and cosmetics since a product can have two intended uses. Such products are regulated either as a cosmetic or as a drug depending on the composition of the product (2).

Over recent years, the global cosmetic market is increasing at alarming rate (3), driven by demands from consumers who are increasingly concerned about their appearance. Naturally, from the perspective of the need that could be either physiological or sociological, females tend to place more interest in maintaining their self-images, and due to this fact, cosmetics appeared to be linked with females (4). A number of studies identified evidences for the association between the rate of continuous use of cosmetic products with female especially in the younger age group, who are highly educated and have better economic status $(5,6)$. Although cosmetics can help consumers feel more beautiful, they can cause untoward effects (adverse events). These effects have been associated with a variety of cosmetic products for several reasons including the following: sensitivities to specific ingredients or the product formulation, microbial contamination product, misuse due to inadequate labeling, color additive violations and also certain cosmetic ingredients (such as fragrances and preservative) that containing unsafe or hazardous substances. It has been suggested that the presence of multiple ingredients and their cumulative effects in the cosmetic products are the top causes of toxicity exposure to consumers (7- 9).

To counteract these effects, food, drug and cosmetics regulatory authorities have consistently advised manufacturers to use whatever testing which is necessary to ensure the safety of their products and ingredients. In line with this, manufacturers and importers have a legal responsibility to ensure products are safe and do not pose a risk to the users.
On top of that, cosmetics consumers are highly recommended to follow some safety tips. This includes reading expiration dates and ingredients on the labels, not sharing cosmetic products, consuming products hygienically and with fewer ingredients, and shopping from the right sources (10-12).

Adverse events associated with cosmetics use can cause the following clinical symptoms including conjunctivitis, cosmetic acne, photo-allergic/toxic contact dermatitis, hypo/hyper pigmentation, itching, corrosive scalp injury, acute hair loss, loosening of nails from the nail bed and irritation of the mucous membrane of the oral cavity (13-15). These reactions can happen immediately after application or on longterm usage. A number of studies addressed cosmetic use and its adverse events. For instance, a study from Naples' urban reported, among 2716 females, $98.5 \%$ used cosmetic products and of them, $26.5 \%$ participants' experienced adverse events (16). In Ethiopia, a study from Mekelle University revealed that $97.8 \%$ had a habit of using cosmetics, of whom $18.4 \%$ encountered cosmetics related adverse events primarily due to deodorants and lotion (17). Furthermore, a study from Wollo University showed that among 220 female students, $97.3 \%$ had a habit of using one or more cosmetics, and $31.8 \%$ of the users reported they experienced adverse events primarily from lotions and body creams (18).

In principle, cosmetics regulatory authorities tried to minimize the unwanted reactions of cosmetics, by setting criteria for safety, efficacy, and quality of cosmetics $(1,10,11)$. Nevertheless, selling products without the authorities' approval, lack of population awareness about proper use of cosmetics and lack of proper adverse effect reporting systems are still prevailing factors particularly in developing countries. As literature indicated, while usage of cosmetic is the increasing trend (3), at the same time, a large number of cosmetic users was threatened with cosmetic related adverse events (16-19). Moreover, females are most likely affected because they tend to use more cosmetic products than men (4-6).

There are few studies addressing cosmetic utilization and its adverse events in the Ethiopian set up (1719). The target population for previous studies were university female students $(17,18)$ and females in the general population (19). However, cosmetic use and its adverse effect could differ among employees due 
to their income status, educational level, access to information and other background characteristics. Therefore, the purpose of this study was to assess cosmetic utilization, its related adverse events and predictors for possible adverse events among female employee in Jimma University, Southwest Ethiopia. Moreover, from an economic point of view and the multiplicity of cosmetic products, any evaluation of the products as well as sensitization to the consumers should be based on complaints from cosmetics users. Therefore, this findings will help Food, Medicine and Health Care Administration and Control Authority (FMHACA) in supplementing the information about cosmetic related adverse events, and it will serve as baseline information for health education in creating public awareness in the study area and for further study.

\section{METHODS AND PARTICIPANTS}

Study setting: The study was conducted at Jimma University, from December, 26, 2016 - January 30, 2017. The University is located in Jimma Town that is about $352 \mathrm{~km}$ Southwest of Addis Ababa. The University is one of the largest Universities in Ethiopia and has three main campuses, which are further organized into six colleges, one specialized hospital and two institutes. The university had 5,478 employees, of whom 3,543 were female employees during the study period.

Study design: A cross-sectional study design was used to assess cosmetics utilization pattern and related adverse events among the university's female employees. This is because the primary aim of this study was to address the magnitude of cosmetic utilization and adverse events.

Study population: A sample of female academic, administrative and health professionals in the hospital of the university were included into the study to address the objective. Female employees who refused to participate were excluded from the survey.

Sampling: The required sample size was determined by single population proportion formula, taking in to account the proportion of female employees experiencing use of at least one cosmetics as $50 \%$. Considering $95 \%$ confidence level, $5 \%$ margin of error and a $10 \%$ non-response rate (20), the final sample size (426) was calculated.
Female employees were stratified into academic, administrative and health professionals in the hospital based on their roles. The sample size was allocated proportionally to the size of employees in the stratum, and the allocated sample size was recruited using random sampling method. Accordingly, 58 academic staffs, 327 administrative staffs and 41 health professionals in the hospital were required to participate in the survey. The list of female employees was obtained from Human Resources Office of the university.

Variables: Self-reported adverse events is considered as a dependent variable. Females experiencing any adverse events following application of any cosmetic product were considered as an adverse event. Demographic characteristics of the employees like age, monthly income, education level and working position were independent variables. Likewise, cosmetic product related characteristic like purpose of use, frequency of use, number of cosmetics applied per day, source of cosmetics, reading information on the containers, following user instruction, adding water or other agents to cosmetic products, prior testing of cosmetic product, sharing cosmetics with others and concomitant traditional cosmetics use were also considered as independent variables.

Data collection procedure: The data collection tool was adapted from previous studies (17-18), and selfadminister questionnaire was used to collect data. The self-administered structured questionnaire was prepared in English and distributed to participants without translation. The questionnaire has three main parts. Part one was about general socio-demographic information of the study participants, part two addressed cosmetics utilization pattern. The last part dealt with participants experience at any time in the past about cosmetics-related adverse events prior to data collection.

Two trained pharmacists who could speak Amharic, Oromifa and English distributed the questionnaire to the participants. The investigators and two pharmacists recruited the participants from the university. Selected participants were given orientation on how to fill in a questionnaire and when to return it.

Data processing and analysis: Data were edited before entry to a computer. Data entry was performed by the principal investigator to Epi info 3.5.1 and analyzed using Statistical Package for

DOI: http://dx.doi.org/10.4314/ejhs.v28i6.6 
Social Sciences (SPSS) software version 21. Descriptive statistics was used to summarize the pattern of cosmetic use, adverse events and demographic characteristics. Logistic regression model was used to assess the determinants of occurrence of cosmetics-related adverse events among the respondents. All variables in bivariable logistic regression were entered into multivariable logistic regression. AOR and its $95 \%$ CI was used to show the strength of association and statistical significance of predictors.

Ethical consideration: Ethical clearance was obtained from the Institute of Health, Jimma University Institutional Review Board. Brief and clear information was provided to the respondents about the aim of the study and participation in the study was voluntary. Accordingly, verbal consent was obtained from all participants. Moreover, participants informed clearly their right not to answer any question if they felt not to respond. Confidentiality of the participant information was maintained and the data were used only for research purpose.
Operational definitions: Adverse events in this study was defined as noxious or harmful effect supposed to be related to a cosmetic use according to participants' self-report traditional cosmetics in this study are defined as homemade cosmetics prepared from plant and/or animal products.

\section{RESULTS}

Socio-demographic characteristics: From the 426 study participants who received the questionnaires, 387 responded successfully, which gives a response rate of $90.8 \%$. Out of 387 respondents, $39.0 \%$ were in the age group of 25-29 years with a median age of 28 years. Regarding educational status, the majority $(68.5 \%)$ were above secondary school. Similarly, their working position profile showed that 243(62.8\%) were administrative staff, 53(13.7\%) were academic staff and $54(14.0 \%)$ cleaners. The income profile of female employees showed that the majority, $278(71.9 \%)$, of the participants earned a monthly income of below 3000 Ethiopian Birr (ETB) while the rest earned greater than 3000 ETB (Table $1)$.

Table 1: Socio-demographic characteristics and cosmetic use among female employees of Jimma University, Southwest of Ethiopia, 2017 ( $\mathrm{n}=387)$.

\begin{tabular}{lllll}
\hline \multicolumn{5}{l}{ Cosmetic use } \\
\hline Variables & Categories & Yes (\%) & No (\%) & Frequency (\%) \\
\hline Age (in years) & $18-24$ & $83(89.2)$ & $10(10.8)$ & $93(24)$ \\
& $25-29$ & $130(86.1)$ & $21(13.9)$ & $151(39)$ \\
& $30-34$ & $45(70.3)$ & $19(29.7)$ & $64(16.5)$ \\
Educational status & $\geq 35$ & $52(65.8)$ & $27(34.2)$ & $79(20.4)$ \\
& Grade 1-12 & $77(63.1)$ & $45(36.9)$ & $122(31.5)$ \\
Personal monthly income & Above grade 12 & $233(87.9)$ & $32(12.1)$ & $265(68.5)$ \\
in ETB & -1000 & $81(64.3)$ & $45(35.7)$ & $126(32.6)$ \\
\multirow{4}{*}{ Working category } & $1000-3000$ & $127(83.6)$ & $25(16.4)$ & $152(39.3)$ \\
& $\geq 3000$ & $102(93.6)$ & $7(6.4)$ & $109(28.2)$ \\
& Academic staff & $51(96.2)$ & $2(3.8)$ & $53(13.7)$ \\
& Health professionals & $34(91.9)$ & $3(8.1)$ & $37(9.6)$ \\
& Administrative staff & $197(81.1)$ & $46(18.9)$ & $243(62.8)$ \\
\hline
\end{tabular}

Cosmetic use: Of the 387 study participants, 310 $(80.1 \%)$ had a habit of using some sorts of cosmetic products. Among these, $96(31.0 \%)$ of the users reported that they use it for beautification, followed by $93(30.0 \%)$ for both beautification and enjoyment and $81(26.1 \%)$ for body protection. Regarding the cosmetic products used, $86.8 \%$ of them used lipstick, lotion, toothpaste, or eye makeup, while $15(4.8 \%)$ replied of using deodorant and/or perfume.

The majority of the respondents, $246(79.4 \%)$, utilized cosmetic products routinely on a daily basis. One-third $(33.2 \%)$ of the respondents usually bought cosmetic products from pharmacy 
while $27.4 \%$ bought from local shops. Concerning cosmetics utilization related practices, a larger count of respondents, 192(61.9\%), used traditional cosmetics (like butter, honey, kesil, egg, lemon, and avocado). In addition, $112(36.1 \%)$ of the respondents had a habit of adding water/other agents to cosmetic products. About 138(44.5\%) respondents shared cosmetics with friends and family memebers. In contrast, 288(92.9\%) of the respondents had a habit of reading labels written on cosmetic products, of whom the majority $133(46.0 \%)$ usually read "user instruction, expiry date, brand names, contents and special remarks". However, 112(38.8\%) read only the expiry date. Among study participants, 106(34.2\%) replied that they practiced testing for allergy prior to use of cosmetics (Table 2).

Table 2: Current cosmetic product usage related characteristics among female employees of Jimma University, Southwest Ethiopia, 2017 ( $\mathrm{n}=310)$.

\begin{tabular}{|c|c|c|c|}
\hline Variables & Categories & Frequency & Percentage \\
\hline \multirow[t]{6}{*}{ Purpose of using cosmetics } & Cleaning & 11 & 3.5 \\
\hline & Body protection & 81 & 26.1 \\
\hline & Beautification & 96 & 31.0 \\
\hline & Correcting body odor & 21 & 6.8 \\
\hline & For enjoyment & 8 & 2.6 \\
\hline & Beautification and enjoyment & 93 & 30.0 \\
\hline \multirow{4}{*}{ Type of cosmetic product used } & Toothpaste, lotion, lipstick, and eye make up & 269 & 86.8 \\
\hline & Deodorant and perfume & 15 & 4.8 \\
\hline & Body cream and lotion & 10 & 3.2 \\
\hline & Shampoos and conditioner & 6 & 1.9 \\
\hline \multirow{3}{*}{ Frequency of cosmetic use } & Daily & 246 & 79.4 \\
\hline & For special occasion & 2 & .6 \\
\hline & Sometimes & 62 & 20.0 \\
\hline \multirow{5}{*}{ Center for shopping cosmetics } & Cosmetic shop & 28 & 9.0 \\
\hline & Supermarket & 65 & 21.0 \\
\hline & Pharmacy & 103 & 33.2 \\
\hline & Local shop & 85 & 27.4 \\
\hline & Mixed & 29 & 9.4 \\
\hline \multirow{2}{*}{$\begin{array}{l}\text { Usually read information from } \\
\text { container }\end{array}$} & Yes & 288 & 92.9 \\
\hline & No & 22 & 7.1 \\
\hline \multirow{2}{*}{$\begin{array}{l}\text { Test cosmetics for adverse } \\
\text { effect }\end{array}$} & Yes & 106 & 34.2 \\
\hline & No & 204 & 65.8 \\
\hline \multirow{2}{*}{$\begin{array}{l}\text { Shared cosmetic products with } \\
\text { family/friends }\end{array}$} & Yes & 138 & 44.5 \\
\hline & No & 172 & 55.5 \\
\hline \multirow{2}{*}{ Using traditional cosmetics } & Yes & 192 & 61.9 \\
\hline & No & 118 & 38.1 \\
\hline \multirow{2}{*}{$\begin{array}{l}\text { Adding water/other agent to } \\
\text { cosmetics }\end{array}$} & Yes & 112 & 36.1 \\
\hline & No & 198 & 63.9 \\
\hline
\end{tabular}

Cosmetic product-related adverse events: From 310 cosmetic users, $19.0 \%$ self-reported ever experience of at least one adverse event due to cosmetic products. Among those who experienced any adverse events, lotion $(26.3 \%)$, hair cosmetics $(14.0 \%)$, body cream and lotions $(11.0 \%)$, and deodorants $(7.0 \%)$ used before the adverse events were mentioned as attributes for the events. According to their report, most adverse events were manifested as breakage of hair, body rash, itching, congestion of the nose, sore on the scalp, redness of the eye, and lip crack. Most affected body parts of the female employees were the face $(36.8 \%)$, followed by all body parts $(14.0 \%)$, hair $(12.3 \%)$, and nose $(12.3 \%)$. In relation to this, the majority $(59.6 \%)$ of the respondents solved the problem by stopping use of the suspected cosmetic product, $14.0 \%$ sought for medical consultation, $17.5 \%$ permanently stopped using any cosmetic products,

DOI: http://dx.doi.org/10.4314/ejhs.v28i6.6 
and $8.8 \%$ stopped use of the products only until the symptoms of the injuries recovered.

Predictors of cosmetic adverse events: We have attempted to identify predictors for cosmetic adverse events among female employees. Three demographic and economic as well as seven cosmetic related variables were entered into multivariable logistic regression analysis using backward logistic regression selection method and the results are summarized in (Table 3). Accordingly, higher personal monthly income and use of traditional cosmetics were found to be statistically significant predictors for cosmetic adverse events experience. The occurrence of cosmetics-related adverse events was observed to increase by a factor of greater than three for female employees who had monthly income between 1000 and 3000 ETB $(\mathrm{AOR}=3.4 ; 95 \% \mathrm{CI}$ : 1.4-8.4), and increase by a factor of greater than five for those who had monthly income above $3000 \mathrm{ETB}$ $(\mathrm{AOR}=4.7 ; 95 \% \mathrm{CI}: 1.8-12.2)$ than those who had less than 1000 ETB.

Female employees who had a habit of using traditional cosmetics were greater than four times likely to experience cosmetic adverse events than non-users of these materials $(\mathrm{AOR}=4.5 ; 95 \% \mathrm{CI}$ : 2.1-9.6). However, habit of testing cosmetic product indicated insignificant relation to their experience of cosmetic adverse events.

Table 3: Demographic and cosmetic related predictors for cosmetic adverse events among female employees of Jimma University, Southwest Ethiopia, $2017(\mathrm{n}=310)$.

\begin{tabular}{|c|c|c|c|c|c|c|}
\hline \multirow[b]{2}{*}{ Variables } & \multirow[b]{2}{*}{ Categories } & \multicolumn{2}{|c|}{$\begin{array}{l}\text { Cosmetic adverse events } \\
\text { experience }\end{array}$} & \multirow[t]{2}{*}{$\operatorname{COR}(95 \% \mathrm{CI})$} & \multirow[t]{2}{*}{$\begin{array}{c}\mathrm{P}- \\
\text { value }\end{array}$} & \multirow[t]{2}{*}{$\operatorname{AOR}(95 \% \mathrm{CI})$} \\
\hline & & Yes $(\%)$ & No $(\%)$ & & & \\
\hline \multirow[t]{4}{*}{ Age (in years) } & $18-24$ & $11(13.3)$ & $72(86.7)$ & 1.00 & .415 & \\
\hline & $25-29$ & $29(22.3)$ & $101(77.7)$ & $1.9(.9,4.0)$ & .102 & \\
\hline & $30-34$ & $8(17.8)$ & $37(82.2)$ & $1.4(.5,3.8)$ & .493 & \\
\hline & $\geq 35$ & $11(21.2)$ & $41(78.8)$ & $1.8(.7,4.4)$ & .230 & \\
\hline \multirow[t]{2}{*}{ Educational status } & Grade 1-12 & $12(15.6)$ & $65(84.4)$ & 1.00 & & \\
\hline & $>$ grade 12 & $47(20.2)$ & $186(79.8)$ & $1.4(.7,2.7)$ & .375 & \\
\hline **Personal monthly & $<1000$ & $7(8.6)$ & $74(97.4)$ & 1.00 & .029 & \\
\hline \multirow[t]{2}{*}{ income in ETB } & $1000-3000$ & $29(22.8)$ & $98(77.2)$ & $3.1(1.3,7.5)$ & .011 & $3.4(1.4,8.4)$ \\
\hline & $\geq 3000$ & $23(22.5)$ & $79(77.5)$ & $3.1(1.2,7.6)$ & .015 & $4.7(1.8,12.2)$ \\
\hline \multirow[t]{2}{*}{ Daily use of cosmetics } & Yes & $51(20.7)$ & $195(79.3)$ & $1.8(.8,4.1)$ & .140 & \\
\hline & No & $8(12.5)$ & $56(87.5)$ & & & \\
\hline Usual number of & $1-2$ & $8(10)$ & $72(90)$ & & .056 & \\
\hline \multirow[t]{2}{*}{ cosmetics used at times } & 3 & $18(20.2)$ & $71(79.8)$ & $2.3(.9,5.6)$ & .071 & \\
\hline & $\geq 4$ & $33(23.4)$ & $108(76.6)$ & $2.8(1.2,6.3)$ & .017 & \\
\hline \multirow[t]{5}{*}{ Usual shopping center } & Local shop & $13(15.3)$ & $72(84.7)$ & 1.00 & .043 & \\
\hline & Supermarket & $8(12.3)$ & $57(87.7)$ & $.8(.3,2.0)$ & .602 & \\
\hline & Pharmacy & $20(19.4)$ & $83(80.6)$ & $1.3(.6,2.9)$ & .460 & \\
\hline & $\begin{array}{l}\text { Cosmetic } \\
\text { shop }\end{array}$ & $11(39.3)$ & $17(60.7)$ & $3.6(1.4,9.4)$ & .009 & \\
\hline & Mixed & $7(24.1)$ & $22(75.9)$ & $1.8(.6,5.0)$ & .284 & \\
\hline$* *$ Used traditional & Yes & $49(25.5)$ & $143(74.5)$ & $3.7(1.8,7.6)$ & .001 & $4.5(2.1,9.6)$ \\
\hline cosmetic & No & $10(8.5)$ & $108(91.5)$ & 1.00 & & \\
\hline Ever added water or other & Yes & $21(18.8)$ & $91(81.2)$ & $.97(.5,1.6)$ & .924 & \\
\hline agent to cosmetics & No & $38(19.2)$ & $160(80.8)$ & 1.00 & & \\
\hline Shared cosmetics with & Yes & $29(21)$ & 109(79) & $1.3(.7,2.2)$ & .426 & \\
\hline family and/or friends & No & $30(17.4)$ & $142(82.6)$ & 1.00 & & \\
\hline *Cosmetic adverse & Yes & $26(24.5)$ & $80(75.5)$ & $1.7(.9,3.0)$ & .077 & $.6(.3,1.1)$ \\
\hline reaction tested & No & $33(16.2)$ & $171(73.8)$ & 1.00 & 1.00 & \\
\hline
\end{tabular}

* variable remained within the final model but not statistically significant ** variables significant in final model 


\section{DISCUSSION}

Eight from ten female employees of Jimma University usually use cosmetics product for beautification, cleaning, or other purposes. Near to $1 / 5^{\text {th }}$ of female cosmetic users develop at least one adverse events due to cosmetic product usage in the university. Personal monthly income and use of traditional cosmetic were predictors for developing cosmetic related adverse events.

In this study, the magnitude of cosmetics uses was $310(80.1 \%)$. This was lower than studies in female students from other parts of the Ethiopia $(17,18)$. This can be explained partly by age differences of the study participants. Due to their young age, students are more concerned about their appearance and beauty, which might increase the demand for cosmetics use than others.

Concerning the self-reported adverse events, $19.0 \%$ of the female employees complained adverse events. Lotions were the most $(26.3 \%)$ complained about cosmetic product followed by hair cosmetics, body cream and deodorants. This finding was consistent with findings in a study-conducted in Mekelle University (17). In this study, face and hair were the most affected body parts by cosmetics adverse events. Again, this finding is supported by literature $(15,17)$.

In this study, the occurrence of cosmeticsrelated adverse events increased by a factor of greater than four for female employees who were using traditional cosmetics as compared to nonusers. This result is in line with a study done in Wollo University female students (18). This might be due to the increased cosmetics burden and possible interaction among the multiple cosmetics ingredients including traditional cosmetics. Mixing any agents to the cosmetic products could contaminate and is prone to microbial infection. In addition, the cumulative interaction between the added agent and cosmetic ingredients could lead to any adverse events $(7,8)$. Hence, use of traditional cosmetics by mixing with others, could also follow the same principle and lead to adverse events. Specific interaction of the prior mentioned home preparations could require a further risk assessment. Even though there was no significant association between sharing cosmetic products and the adverse events; from the total female employees, nearly half $(44.5 \%)$ shared cosmetics with friends and family members. Sharing is known to make cosmetic products prone to microbial contamination that in turn causes acne and other infection $(7,8)$. Nevertheless, the disadvantage of such practice must be advised to the female employees. Greater than half of $(65.8 \%)$ female employees did not practice testing for allergy.

Female employees who have a monthly income between 1000 and $3000 \mathrm{ETB}(\mathrm{AOR}=3.4)$ and above 3000 ETB $(\mathrm{AOR}=4.7)$ were more likely to develop adverse events as compared to employees whose monthly income was less than 1000 ETB. This is similar with findings from study done in Mekelle and Wollo universities among female students $(17,18)$. This might be related to use of many types and number of cosmetic products since they can afford to purchase. Females who had a number of varieties of cosmetic products at hand could over use. Using multiple cosmetics at a time, might increase synergistic action of cosmetic products or increase the concentration of ingredients above the limit (15) which might lead to adverse events.

This study could have its own limitation, and users should consider this when interpreting the evidences. First, the estimates about cosmetic related adverse event were based on the self-report of participants, which could be affected by recall bias and in turn lead to under-estimation. Second, participants' perceived that the cause of the adverse events might not be related to cosmetic products. Third, the data collection instrument was in English language, other than the local language, which might affect the validity of our data. Lastly, the nature of cross sectional study is weak to determine causal association between the experienced cosmetic related adverse event and exposure variables like use of traditional cosmetics and monthly income of participants. To minimize the possible recall bias, the common cosmetic products and possible adverse events were predefined in the questionnaire. Similarly, incomplete data about cosmetic use status and its adverse events were not considered during analysis.

In conclusion, many of the female employees of Jimma University were using any cosmetic products, and a significant numbers of them were experiencing cosmetic related adverse events. Face and hair were the most affected body parts of female employees by cosmetics adverse events. High personal monthly income and use of traditional cosmetics were predictors for experiencing adverse events due to cosmetics. During health information dissemination programs about safety tips on proper cosmetic use,

DOI: http://dx.doi.org/10.4314/ejhs.v28i6.6 
emphasis should be given to employees who have high income and use traditional cosmetics.

\section{ACKNOWLEDGMENTS}

We would like to thank Jimma University for the provision of all-rounded support. We would like to express our deepest gratitude to the study participants and the data collectors. Our appreciation also goes to Dr. Zeleke Mekonnen, Mr. Million Tesfaye, Mr. Mio Ayana and Mr Daniel Dana for sharing their valuable knowledge and advice on the project.

\section{REFERENCES}

1. Ethiopian Food, Medicine and Healthcare Administration and Control Authority (FMHACA). Cosmetics and Sanitary Items Directive 2014. Available at: http://www.fmhaca.gov.et/documents/Cosmetics $\%$ 20and\%20Sanitary\%20Items\%20 Directive.pdf.

2. Is It a Cosmetic, a Drug, or Both? https://www.fda.gov/Cosmetics/GuidanceRegulati on/LawsRegulations/ucm074201.htm

3. Research and Markets: Global Cosmetics Market 2015-2020. Available online: http://www.businesswire.com/news/home/2015072 7005524/en/Research-Markets-Global-CosmeticsMarket-2015-2020-Market (accessed on December 16,2016).

4. Fatehi A, Ekhlasi E. Body management and its relationship with social acceptance of body. Women's Strategic Studies (KetabeZanan) 2008; 11:9-42.

5. Dehghan R, Talaee R, Sehat M, Ghamsari NN, Mesgari L. Surveying the Rate of Using Cosmetics Among the Kashan's Women. Journal of Biology and Today's World 2017; 6(2): 27-32

6. Jalilian F, Ahmadpanah M, Karimi M, Salehi A, Vahidnia EA, Emdadi SH. Prevalence and reasons for cosmetic products use among female students in Hamedan universities. Journal of Dermatology and Cosmetics 2012; 3 (1):9-15.

7. Lundov MD, Moesby L, Zachariae C, Johansen JD. Contamination versus preservation of cosmetics: a review on legislation, usage, infections, and contact allergy. Contact Dermatitis, 2009; 60(2):70-8.

8. Hugbo G, Anthony O, Onyekwe L, Ijoma I. "Microbial contamination and preservative capacity of some brands of cosmetic creams," Tropical Journal of Pharmaceutical Research 2003; 2: 229-234.

9. Tomar J, Jain VK, Aggarwal K, Dayal S, Gupta S. Contact allergies to cosmetics: testing with 52 cosmetic ingredients and personal products. $J$ Dermatol 2005; 32(12):951-955.

10. European Commission. Regulation (EC) No. 1223/2009 of the European Parliament and of the Council of 30 November 2009 on cosmetic products, 2009.

http://eurlex.europa.eu/LexUriServ/LexUriServ.do ?uri=OJ:L:2009:342:0059:0209:en

11. FDA Regulation of Cosmetics and Personal Care Products July 9, 2012 Congressional Research Service.

12. Kumar S,Gupta RN. Adverse events of cosmetic products: regulatory challenges in India. Int $J$ Pharm Bio Sci 2014 ; 5(1): 83- 93.

13. Salverda JG, Bragt PJ, Wit-Bos L. de, et al. Results of a cosmetovigilance survey in The Netherlands. Contact Dermatitis 2013; 68(3): 139.

14. Mehta SS, Reddy BS. Cosmetic dermatitis: Current perspectives. Int J Dermatol 2003; 42:533-42.

15. Nigam PK. Adverse events to cosmetics and methods of testing. Indian $J$ Dermatol Venereol Leprol, 2009; 75:10-19.

16. Di Giovanni C, Arcoraci V, Gambardella L, Sautebin L. Cosmetovigilance survey. Are cosmetics considered safe by consumers? Pharmacological Research 2006; 53:1, 16-21.

17. Dibaba H, Yadesa D, Legesse B, Shewamene Z, W/Gerima B. Cosmetics utilization pattern and related adverse reactions among female University students. IJPSR 2013; 4: 998-1003.

18. Meharie BG, Ambaye AS, Thaimanot YM, et al. A cross sectional study on assessment of cosmetics utilization and self-reported adverse events among Wollo University, Dessie Campus Female Students, Dessie, North East Ethiopia. Eur $J$ Pharm Med Res, 2014; 2:49-63.

19. Bilal AI, Tilahun Z, Shimels T, Gelan Y, D. Osman E. Cosmetics Use-Related Adverse Events and Determinants Among Jigjiga Town Residents, Eastern Ethiopia. Dermatol Ther (Heidelb) 2017; 7(1): 143-153.

20. Daniel W. Biostatistics. A foundation for analysis in health science, $6^{\text {th }}$ Ed. NewYork,7-10. 